\title{
Minimum Thickness
}

National Cancer Institute

\section{Source}

National Cancer Institute. Minimum Thickness. NCI Thesaurus. Code C120720.

The minimum value in a range of values that describe the thickness of an entity. 